\title{
Manifestations of pilocytic astrocytoma: a pictorial review
}

\author{
Danai Chourmouzi • Elissabet Papadopoulou • Manolis Konstantinidis • \\ Vasileios Syrris • Kostas Kouskouras • Afroditi Haritanti • George Karkavelas • \\ Antonios Drevelegas
}

Received: 25 October 2013 /Revised: 26 March 2014 / Accepted: 27 March 2014 / Published online: 2 May 2014

(C) The Author(s) 2014. This article is published with open access at Springerlink.com

\begin{abstract}
Background Pilocytic astrocytoma can be challenging to diagnose.

Methods Its clinical presentations can differ, directly related to its size and location, and are relatively unreliable. Similarly, imaging findings also vary with the location of the pilocytic astrocytoma. Results This review provides an overview of the different imaging findings regarding pilocytic astrocytomas using both conventional and advanced magnetic resonance imaging sequences according to tumour location; the findings are strongly related to the tumour's tendency to infiltrate surrounding structures, being able to carry out gross total resection, and finally the prognosis.

Conclusions Knowledge of these imaging manifestations of pilocytic astrocytoma may be helpful to arrive at an accurate diagnosis.

\section{Teaching Points}

- To recognise the various imaging findings of pilocytic astrocytoma on both conventional and advanced magnetic resonance imaging sequences.

- To identify the characteristic imaging findings according to tumour location.

- To discuss the relevant differential diagnoses of pilocytic astrocytoma in each tumour location.
\end{abstract}

D. Chourmouzi $(\bowtie) \cdot$ E. Papadopoulou $\cdot$ M. Konstantinidis $\cdot$

V. Syrris

Department of Radiology, Interbalcan Medical Centre, Thessaloniki, Greece

e-mail: dchourm@hol.gr

K. Kouskouras $\cdot$ A. Haritanti $\cdot$ A. Drevelegas

Department of Radiology, Aristotle University of Thessaloniki,

"AHEPA" Hospital, Thessaloniki, Greece

G. Karkavelas

Department of Pathology, School of Medicine, Aristotle University of Thessaloniki, Thessaloniki, Greece
Keywords Pilocytic astrocytoma $\cdot$ Glioma $\cdot$ Magnetic resonance imaging

\section{Introduction}

Pilocytic astrocytoma (PA) is a rare, slow-growing glioma, classified as grade I by the World Health Organisation (WHO); it typically occurs in children and young adults $[1,2]$. PA is the most common glial neoplasm in children. Only one-third of patients are older than 18 years of age and only $17 \%$ are older than 30 years of age. In the paediatric population, two-thirds of lesions are located in the cerebellum; in adults, one-half of tumours are supratentorial $[3,4]$. The cerebellum and the region around the third ventricle are the most common sites of origin; however, the entire neuraxis can be affected, with a preference for the optic nerve, optic chiasma, hypothalamus, cerebellum, brainstem, thalamus, basal ganglia, and cerebral hemispheres [5-7].

There are no clinical features that are unique to these tumours. Signs and symptoms are usually of several months' duration and are directly related to the size, location, and presence of associated hydrocephalus. PAs usually follow an indolent course, with an extremely high survival rate - over $90 \%$ at 10 years of age [8].

The macroscopic appearance of PAs is typically wellcircumscribed, cystlike masses with a discrete mural nodule [9]. The name "pilocytic" (directly translated as "hair cell") is derived from the long, hair-like projections that emanate from the neoplastic astrocytes. Microscopically, this tumour often reveals a biphasic pattern in which more compact areas composed of bipolar areas and brightly eosinophilic Rosenthal fibers alternate with looser, spongier areas with prominent microcysts. Eosinophilic granular bodies are found in both compact and loose areas (Fig. 1a-c). Pleomorphism, 

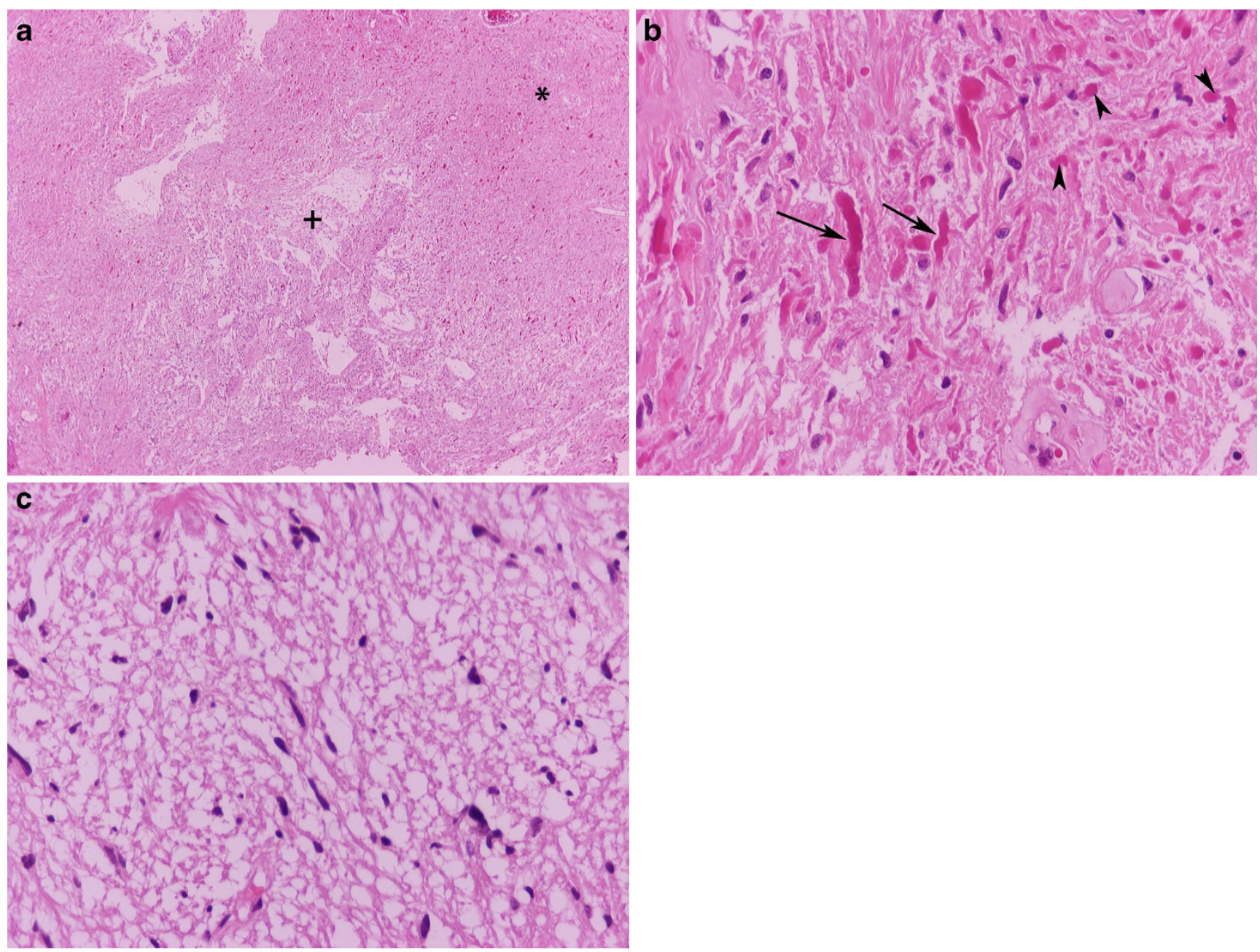

Fig. 1 Pilocytic astrocytoma is characterised by a biphasic compact $(*)$ and looser, microcystic areas (+); haematoxylin \& eosin (H\&E) 40×. b High magnification of eosinophilic granular bodies (arrowheads) and Rosenthal fibers (arrows); H\&E 400×. c Higher magnification of the loose area; H\&E 100×
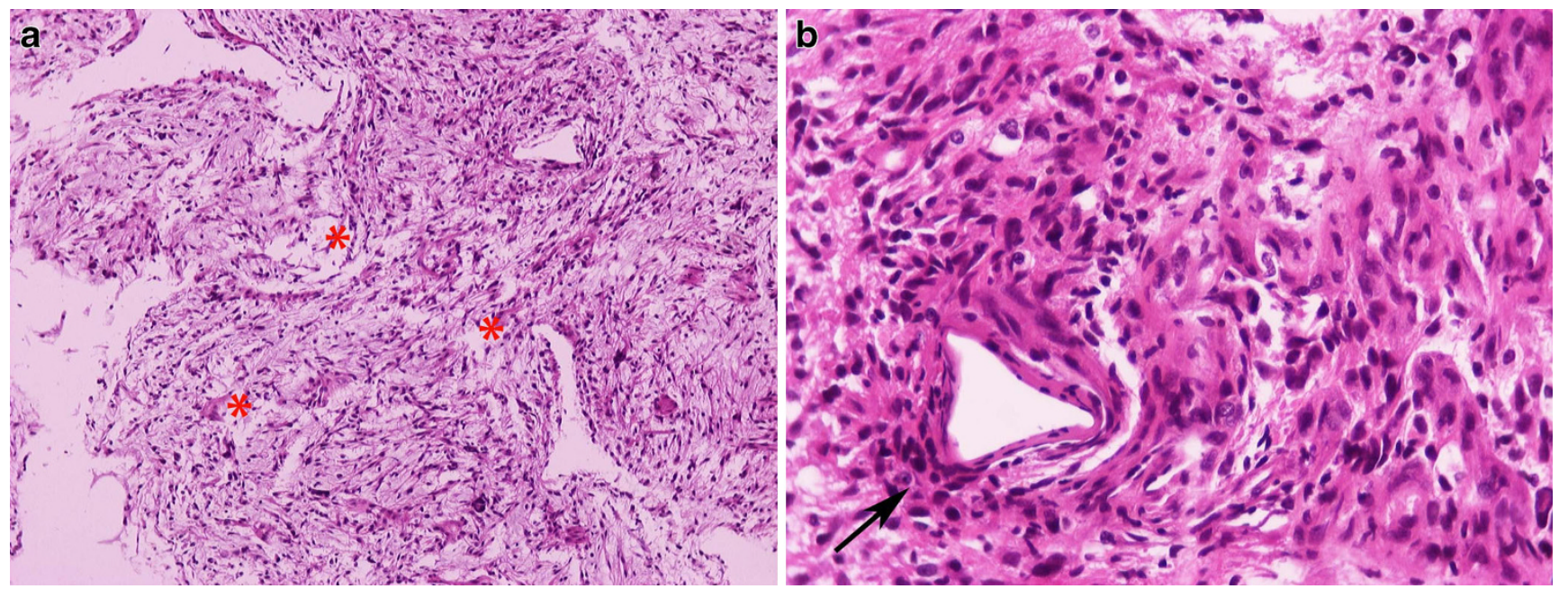

Fig. 2 Pilomyxoid astrocytoma. a Piloid cells in a loose myxoid stroma (asterisks); H\&E 100×. b Perivascular arrangement of neoplastic cells (arrow); 400× 

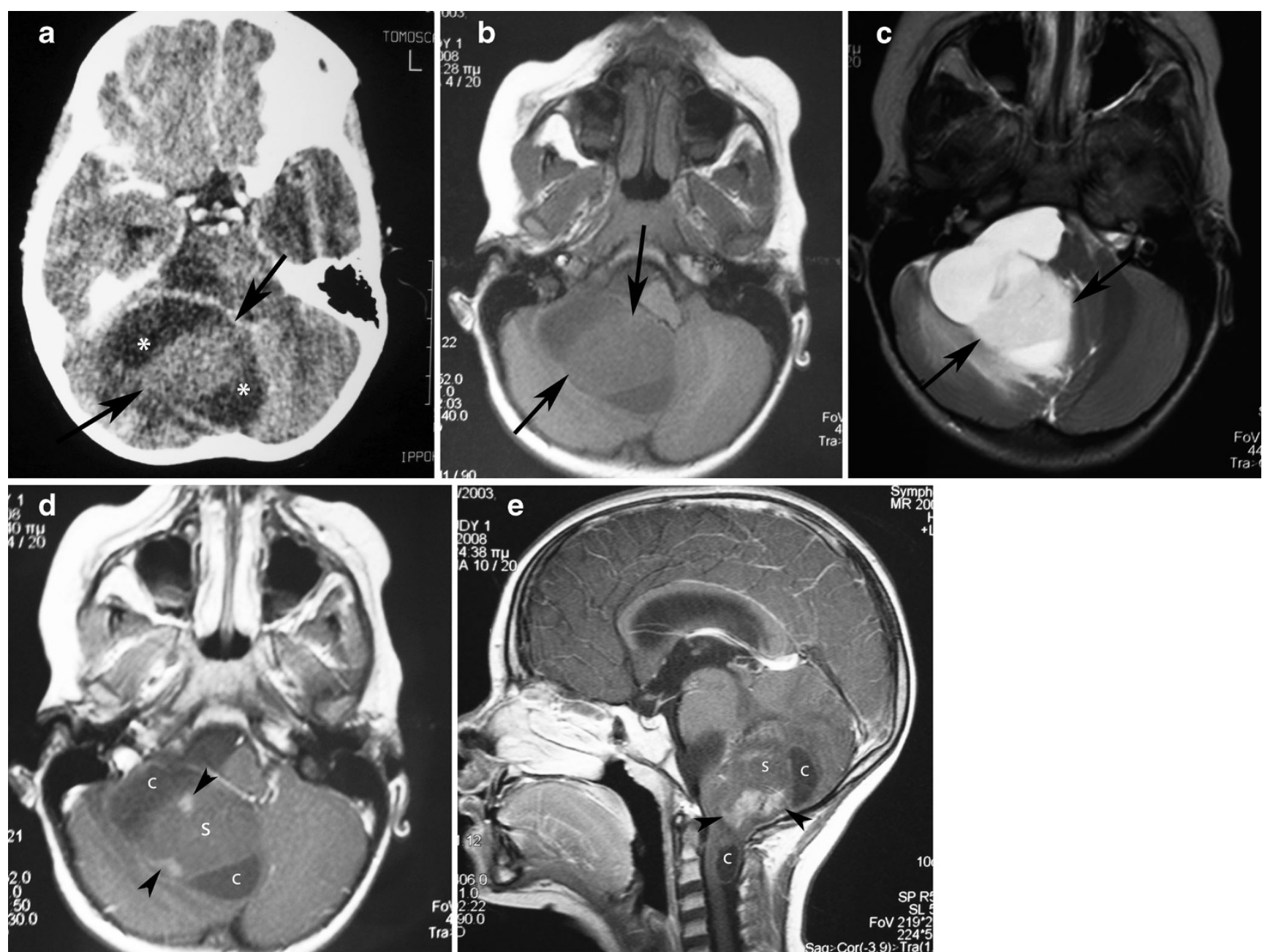

Fig. 3 Juvenile pilocytic astrocytoma of the cerebellum in a 5-year-old girl. a Post-contrast CT shows a cystic lesion involving the right cerebellar hemisphere with a hypodense cystic component (asterisks) and a large, solid, isodense component (arrows). b On axial T1-weighted image, the solid component is homogeneous and hypointense compared with the grey matter (arrows). c On T2-weighted images, the solid component

appears hyperintense compared with the grey matter and slightly hypointense compared with the cerebrospinal fluid (arrows). Post-contrast axial (d) and sagittal (e) images demonstrate heterogeneous enhancement of the solid component of the mass with areas that remain unenhanced (s) and areas with nodular enhancement (arrowheads). Note the cystic components (c)

infrequent mitosis, or vascular proliferation may be observed; however, unlike other astrocytomas, they are rather degenerative and do not have an ominous prognosis. Hyalinisation of the blood vessels is another feature of PAs. Microvascular proliferation of PAs accounts for the contrast enhancement that accompanies these tumours on cross-sectional imaging.

A PA with anaplastic features often contains more than four mitoses per ten high-powered fields, as well as pseudopalisading necrosis. While PAs with anaplastic features do not have defined criteria under the WHO classification, evidence suggests that PAs with anaplastic features and pseudopalisading necrosis behave similarly to $\mathrm{WHO}$ grade 3 neoplasms.
Pilomyxoid astrocytoma (PMA) is a recently described astrocytic tumour that has been previously diagnosed as pilocytic astrocytoma. PMA can be defined as either a variant of PA or a separate entity with monomorphous pilomyxoid characteristics. PMA is a grade II tumour characterised by a prominent myxoid stroma and angiocentric arrangement of neoplastic cells (Fig. 2a, b). More aggressive than PA, PMA more often exhibits local recurrence, as well as cerebrospinal spreading [10].

When imaged in cross section, two-thirds of all PAs demonstrate a classic appearance: a cystic mass with an enhancing mural nodule. However, less common appearances are quite nonspecific. A feature specific of this benign neoplasm is that in many cases it displays histological and imaging features 

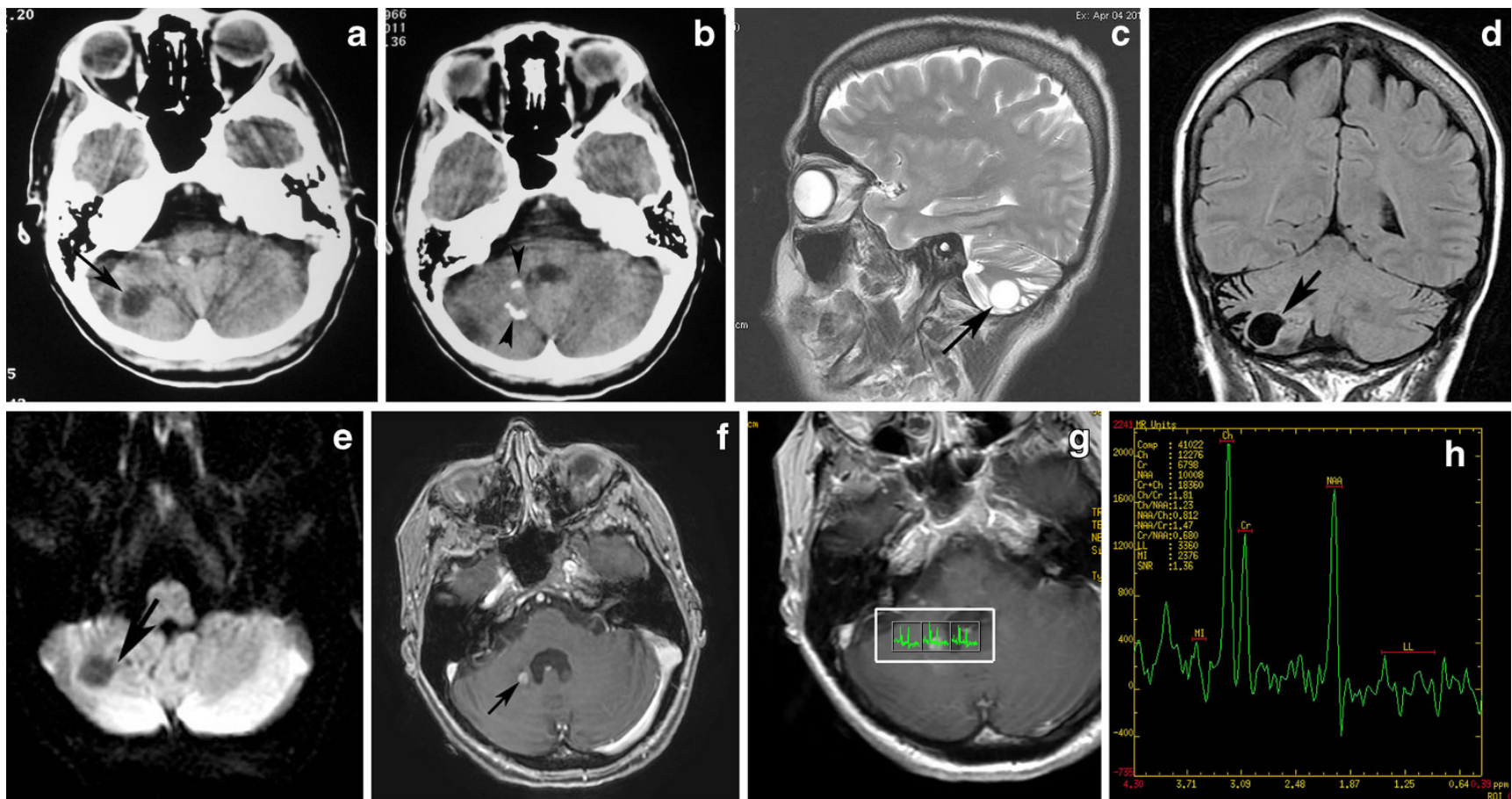

Fig. 4 A pilocytic astrocytoma of the right cerebellar hemisphere incidentally discovered during staging in a 45 -year-old woman with breast cancer. a An axial CT image shows a well-marginated cyst in the right cerebellar hemisphere (arrow). b An axial CT image in a higher level shows fleck-like calcifications (arrowheads). On sagittal T2-weighted (c),

coronal FLAIR (d), and axial diffusion-weighted (e) images, the cyst follows cerebrospinal fluid intensity (arrows). This axial post-contrast T1weighted image (f) depicts an enhancing focus (arrow). On MRS centred on an enhancing nodule with TE 144-ms (g, h), there is mild elevation of choline/Cr, mild reduction of $\mathrm{NAA} / \mathrm{Cr}$, and a small lactate peak

that are commonly seen in higher grade neoplasms and appear incongruous for a slow-growing brain tumour with fairly bland histological characteristics, such as microvascular proliferation, infiltration of surrounding tissues and structures, intratumoral haemorrhage, intense enhancement on post-

contrast images, and leptomeningeal dissemination [2, 9, $11-13]$.

Although gross total resection of the tumour is often curative, location in critical or deep areas (such as the brainstem and hypothalamus) can render it unresectable and require
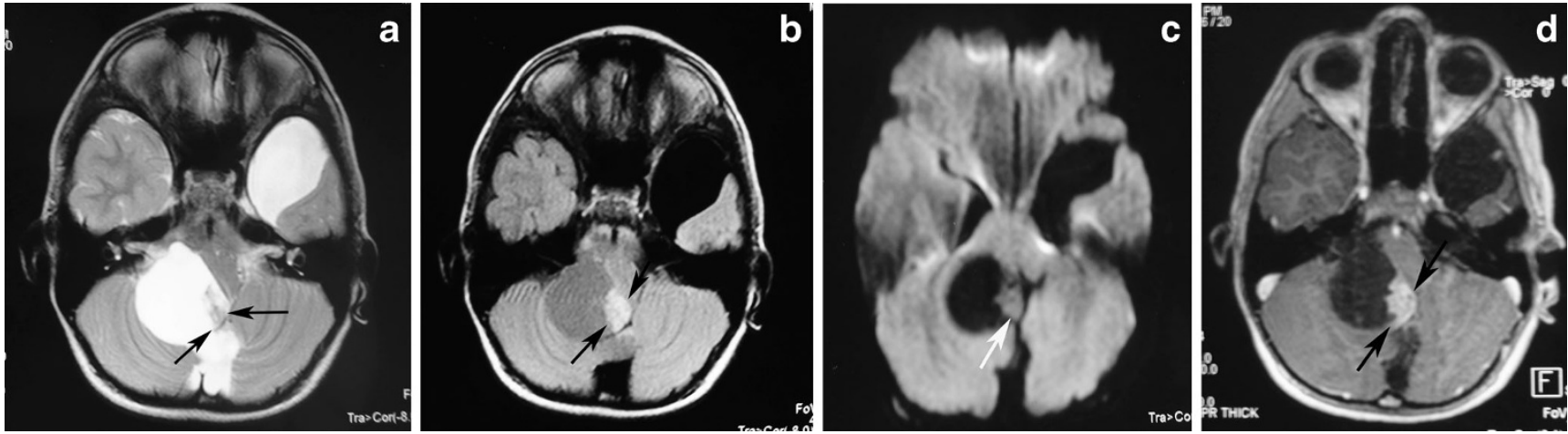

Fig. 5 A large, cystic CPA in a 7-year-old boy. (a) An axial T2-weighted image shows a hyperintense mass of the right cerebellar hemisphere with a less intense soft-tissue nodule along its medial margin and without surrounding oedema (arrows). Note the arachnoid cyst in the left middle cranial fossa. b On an axial FLAIR image, the cystic component shows

low signal intensity that is higher than that of the CSF, and the soft tissue nodule is homogeneous and slightly hyperintense (arrows). c On a diffusion-weighted image, the mural nodule appears isointense (arrow). d An axial, contrast-enhanced, T1-weighted image demonstrates intense enhancement of the mural nodule (arrows) 
Fig. 6 Pilocytic astrocytoma in a 26-year-old woman arising in the vermis. a A sagittal T2-weighted image shows a hyperintense cystic mass of the cerebellar vermis with a peripherally located mural nodule (arrows)

compressing the fourth ventricle. b An axial contrast-enhanced T1weighted image demonstrates intense enhancement of the mural nodule (arrow), as well as cyst wall enhancement (arrowheads)
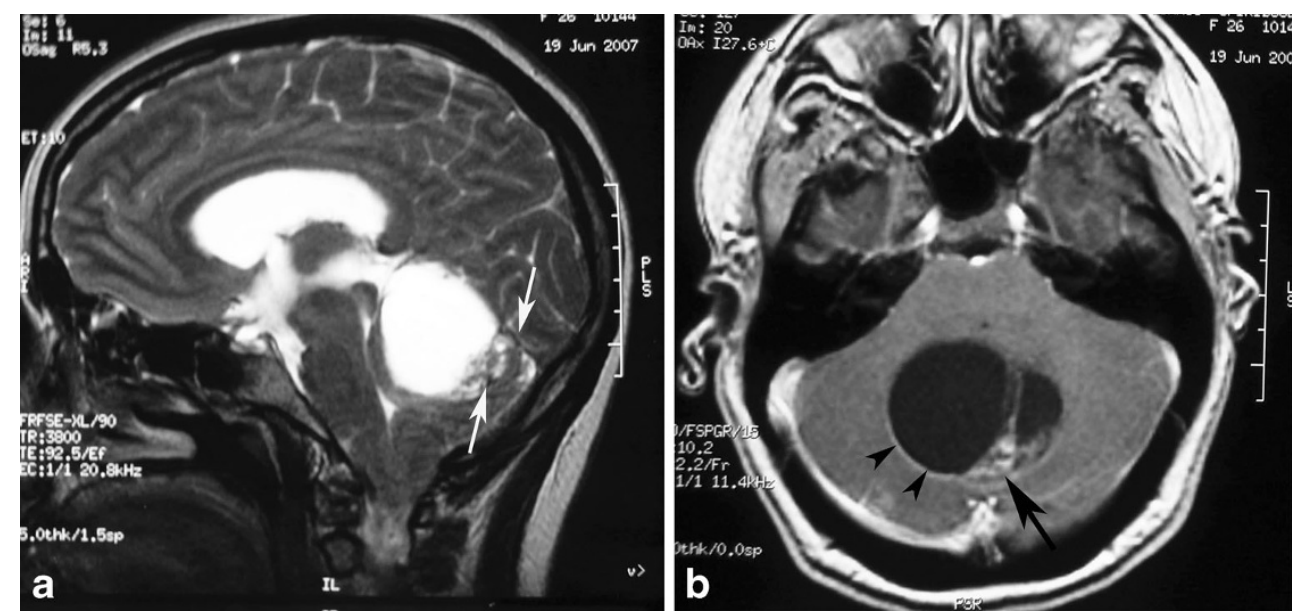

additional management approaches. Strategies for treating PA in critical or deep areas, such as chiasmatic and brainstem PAs, include observation and combinations of surgery, chemotherapy, and radiotherapy. Although pathological diagnosis remains the gold standard, preoperative diagnosis of tumour behaviour and extent is of utmost importance in selecting the appropriate therapeutic management in every single case [14]. Quite often, the diagnosis of PA is initially made or suggested on the basis of an imaging study. Therefore, it is important for all radiologists to be aware of the many clinical and radiological manifestations of this tumour type.

The aim of this pictorial review is to illustrate the wide spectrum of radiologic manifestations of PAs on both conventional and advanced magnetic resonance imaging (MRI) sequences according to tumour location.

\section{Infratentorial manifestations}

\section{Cerebellar PA}

Cerebellar PA (CPA) is the most common cerebellar tumour in children [15]. The peak incidence of CPA is between the ages of 5 and 13 years. CPA occurs with equal frequency in boys and girls. Although CPA is usually sporadic, associations with
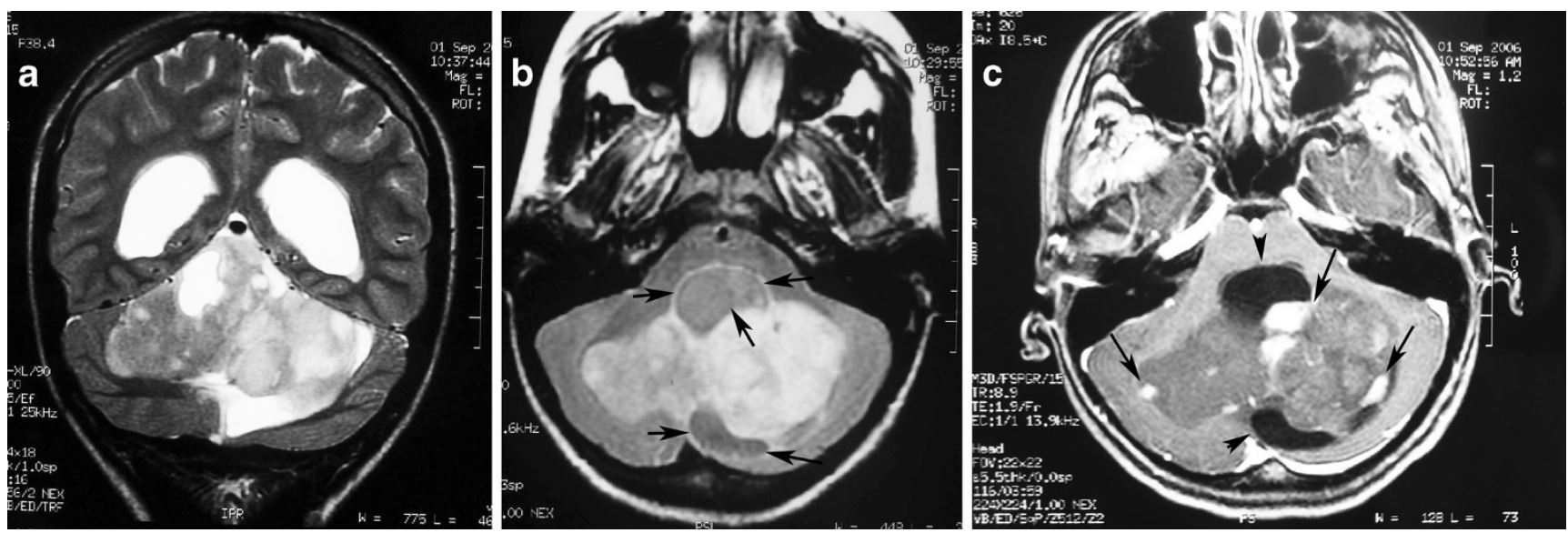

Fig. 7 A pilocytic astrocytoma with a predominantly solid mass and a minimal cyst-like component in a 14-year-old girl. a This coronal T2weighted image shows a large, well-marginated mass, involving the vermis and both cerebellar hemispheres that effaces the fourth ventricle. b On an axial FLAIR image, the solid mass shows high signal intensity with hypointense cystic areas (arrows). c On an axial contrast-enhanced image, the mass shows inhomogeneous contrast enhancement, with nodules that exhibit intense enhancement (arrows) and other cystic areas that remain unenhanced (arrowheads) 

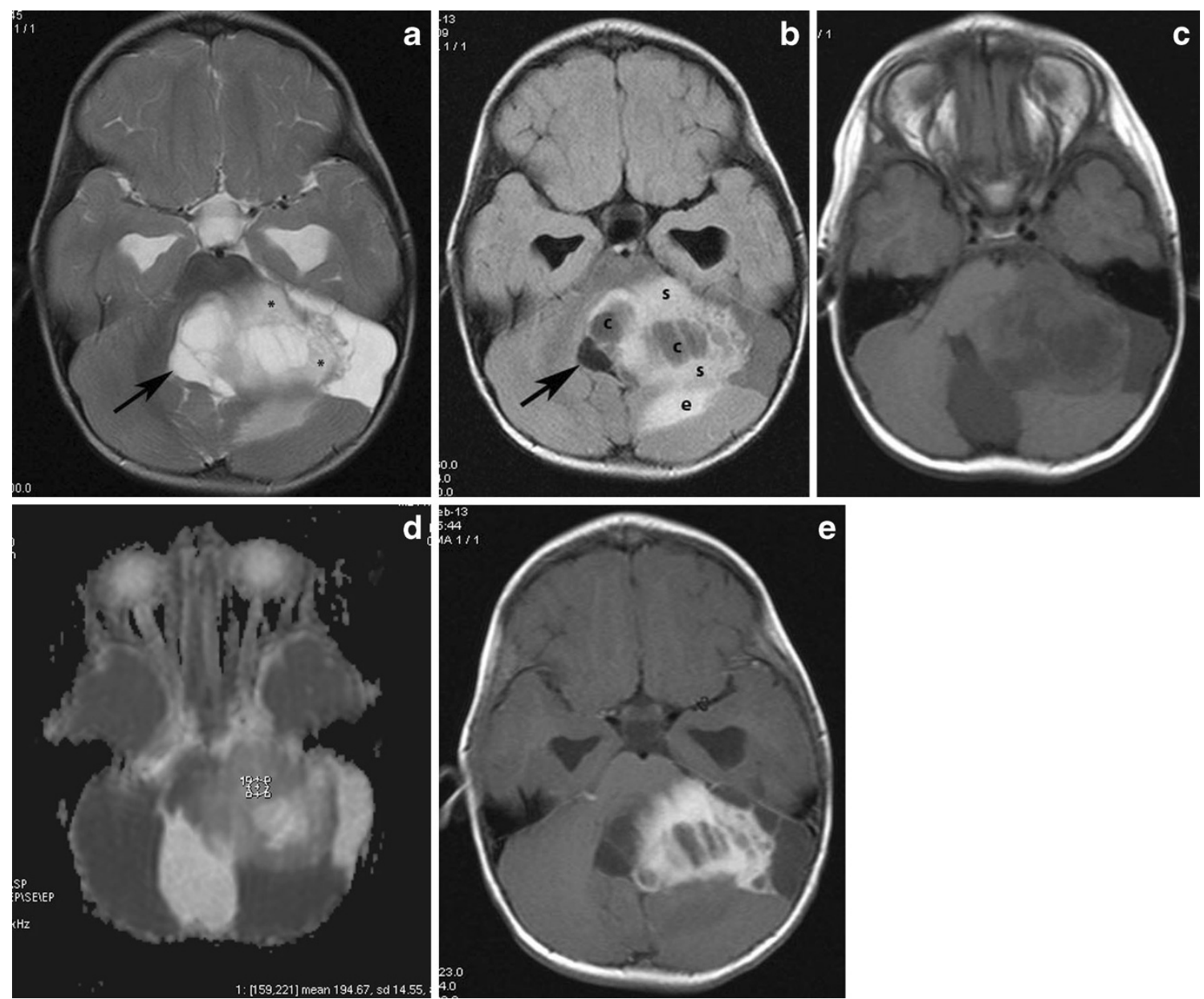

Fig. 8 Pilocytic astrocytoma of the left cerebellar hemisphere with a solid and cystic component severely compressing the fourth ventricle and the medulla, producing obstructive hydrocephalus. a An axial T2-weighted image shows a cystic, hyperintense mass with a less intense solid component (asterisks) compressing the fourth ventricle (arrow). b On a FLAIR image, the cystic component (c) shows low signal intensity, which is higher than that of the CSF, and the solid component (s) shows high

signal intensity. Note the low signal of the compressed fourth ventricle (arrow) and the peritumoral oedema (e). $\mathbf{c}$ On this T1-weighted image, the solid components appear hypointense compared with grey matter. $\mathbf{d}$ The solid component shows high values on an ADC map. e Intense enhancement of solid components is depicted after the administration of a paramagnetic agent

neurofibromatosis type 1, Turcot syndrome, $\operatorname{PHACE}(\mathrm{S})$ syndrome, and Ollier's disease have been reported [16].

There is contradictory evidence in the literature regarding the most common location of PA in the cerebellum. In one series of 132 patients, $16 \%$ of tumours arose in the vermis, $53 \%$ in the cerebellar hemisphere, and $26 \%$ in both; $34 \%$ also involved the brainstem [17]. However, in another review of 168 cases, $71 \%$ of PA tumours were located in the vermis, while $29 \%$ occurred in the hemisphere [18].

Because PA growth is generally slow, affected children usually present with a long history of waxing and waning signs of increased intracranial pressure. Headache, vomiting, gait disturbance, blurred vision, diplopia, and neck pain are common symptoms in patients with CPA [16].

CPAs can be small or very large, and cystic, solid, or solid with a necrotic center. Typical computed tomography (CT) imaging features are a large and predominantly cystic mass arising from the vermis cerebelli or the cerebellar hemispheres. The solid part appears hypodense or isodense (or, less commonly, hyperdense) and enhanced on post-contrast images [18, 19] (Fig. 3a). Tumour calcification is rare, but tends to resemble flecks when it does occur [15] (Fig. 4a,b).

The appearance of PA on MRI is variable and depends on the tumour's size and structure. Four predominant imaging patterns of PA have been described: a mass with a nonenhancing cyst and an intensely enhancing mural nodule (Figs. 4 and 5); a mass with an enhancing cyst wall and an intensely enhancing mural nodule (Fig. 6); a necrotic mass 

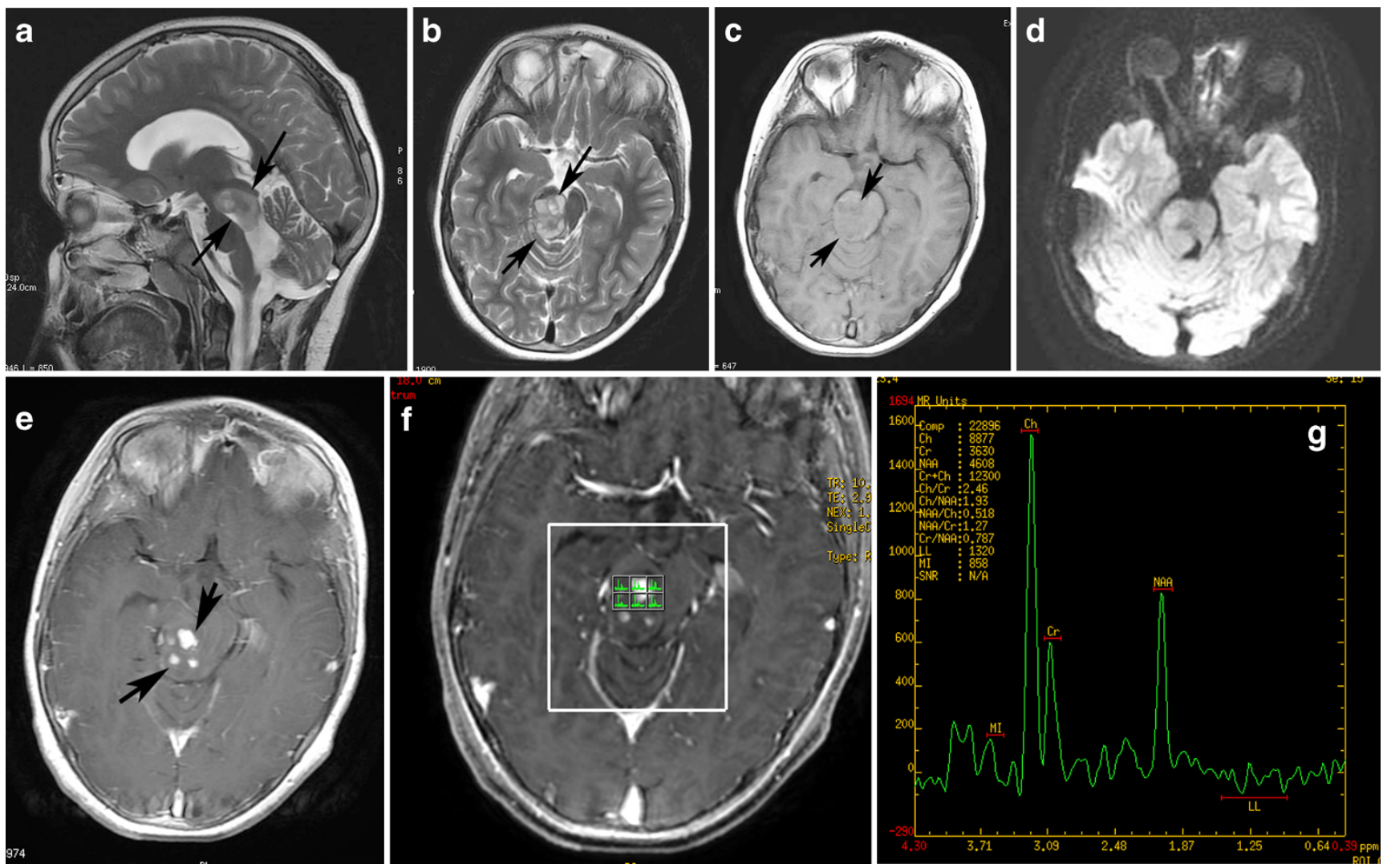

Fig. 9 Focal midbrain glioma, a histopathologically proven pilocytic astrocytoma in an 11-year-old boy. Sagittal (a) and axial (b) T2-weighted images show an exophytic, sharply marginated, hyperintense mass involving the right cerebral peduncle. No surrounding oedema is identified. On this T1-weighted image (c), the mass is isointense compared with grey

matter. The mass is isointense on diffusion-weighted imaging (d). An axial post-contrast image (e) shows heterogeneous enhancement of the tumour. Proton MRS with TE 144-ms (f, g) revealed high choline/Cr (2.46) and NAA/Cr ratios (1.27)

with a central non-enhancing zone; and a predominantly solid mass with minimal to no cystlike component [9] (Figs. 7 and 8). Solid, non-necrotic tumours are less common and account for approximately $10 \%$ of cases. However approximately $50 \%$ of the tumours are cystic, with a mural nodule attached to one part of the cyst wall [15] (Fig. 5).

The solid component of PAs can be homogeneous or heterogeneous. It is usually hypo- to isointense on T1weighted MRI and hyperintense on T2-weighted/FLAIR images compared with grey matter. Compared with the cerebrospinal fluid, the solid component is isointense on T2-weighted images and hyperintense on FLAIR images [20]. After the
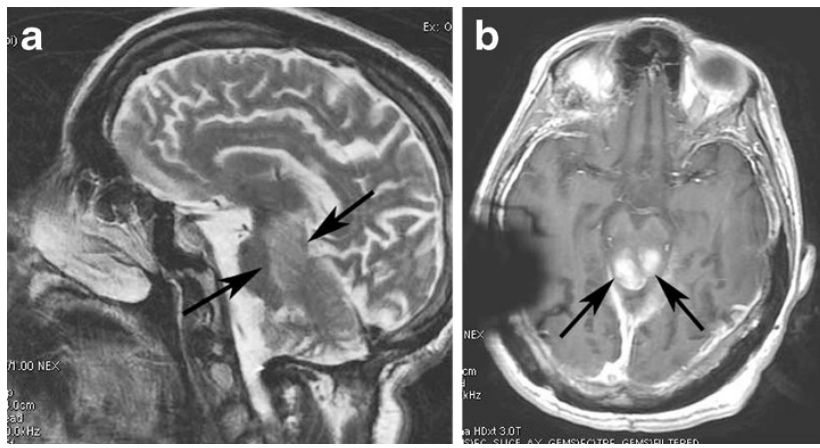

Fig. 10 Midbrain pilocytic astrocytoma in a 20-year-old woman. A sagittal T2-weighted image (a) shows exophytic growth of the tumour. An axial, post-contrast, T1-weighted (b) image shows intense contrast enhancement (arrows). On proton MRS with TE $144 \mathrm{~ms}$ (c, d),
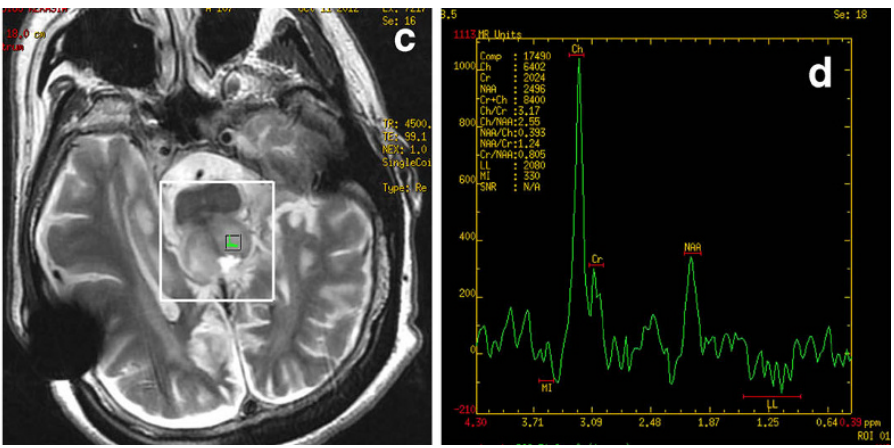

"pseudomalignant" spectrum is observed with an elevated choline peak and reduction of the NAA peak, choline/Cr ratio (3.17), and NAA/Cr ratio (2.55) 

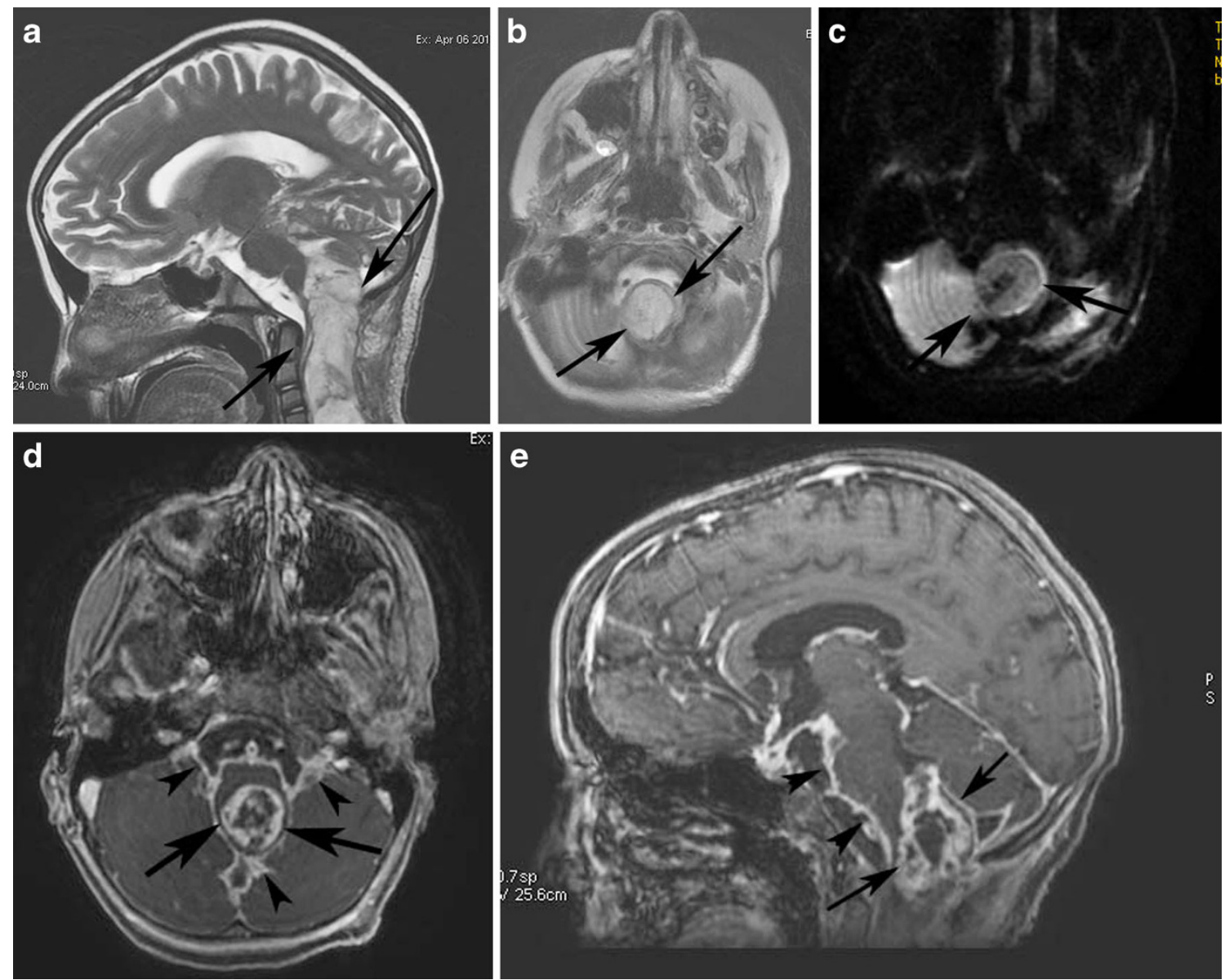

Fig. 11 A pilocytic astrocytoma extending to the upper cervical spine with dissemination after partial resection. a Sagittal T2-weighted and b axial T2-weighted images at the level of the foramen magnum show a high-signal cyst-like mass (arrows). c The lesion is hypointense on diffusion-weighted imaging (arrows). Contrast-enhanced axial (d) and sagittal T1-weighted (e) images of the brain show inhomogeneous enhancement of the mass (arrows), as well as diffuse enhancement of the basilar cisternal spaces (arrowheads) administration of a paramagnetic agent, the solid component of PAs exhibits variable enhancement patterns: areas with prominent enhancement as well as areas that remain unenhanced. Yet the cystic component appears isointense on T1- and T2-weighted images and hyperintense on FLAIR images compared with cerebrospinal fluid (CSF) signal intensity. Enhancement of the cyst wall is not always present and is not necessarily indicative of tumour involvement. Haemorrhages have rarely been reported in PAs and are usually not massive.

On diffusion-weighted imaging, cystic components of the mass exhibit the diffusion properties of CSF. The solid component displays high apparent diffusion coefficient (ADC) values, which indicate the low cellularity of PA [21]. Pavlisa et al. report that $\mathrm{ADC}$ values greater than $120 \times 10^{-5} \mathrm{~mm}^{2} / \mathrm{s}$ are indicative of PA, while an ADC between 80 and $120 \times$ $10^{-5} \mathrm{~mm}^{2} / \mathrm{s}$ is characteristic of ependymoma. Myeloblastoma usually exhibits strong restriction, with $\mathrm{ADC}$ less than $80 \times$ $10^{-5} \mathrm{~mm}^{2} / \mathrm{s}$ [22] (Figs. 4e, 5c and 8d).

Reported studies that employ magnetic resonance spectroscopy (MRS) to examine CPA have revealed high choline, high lactate, and low $\mathrm{N}$-acetylaspartate (NAA) levels, features that are usually associated with highgrade tumours. The presence of lactate within pilocytic tumours might be explained by several mechanisms, such as an abnormal number or dysfunction of mitochondria (which would interfere with the processes of oxidative phosphorylation and electron transport); alterations in proportional oxygen delivery, oxygen extraction, or oxygen usage by the tumour; or anaerobic glycolysis by tumour cells $[23,24]$. However, an in vivo study of PAs using proton MRS by Sutton et al. reported a choline/NAA ratio of 1.80 , which is lower than the ratio observed in other studies [25] (Figs. 4g,h). Although investigators report 

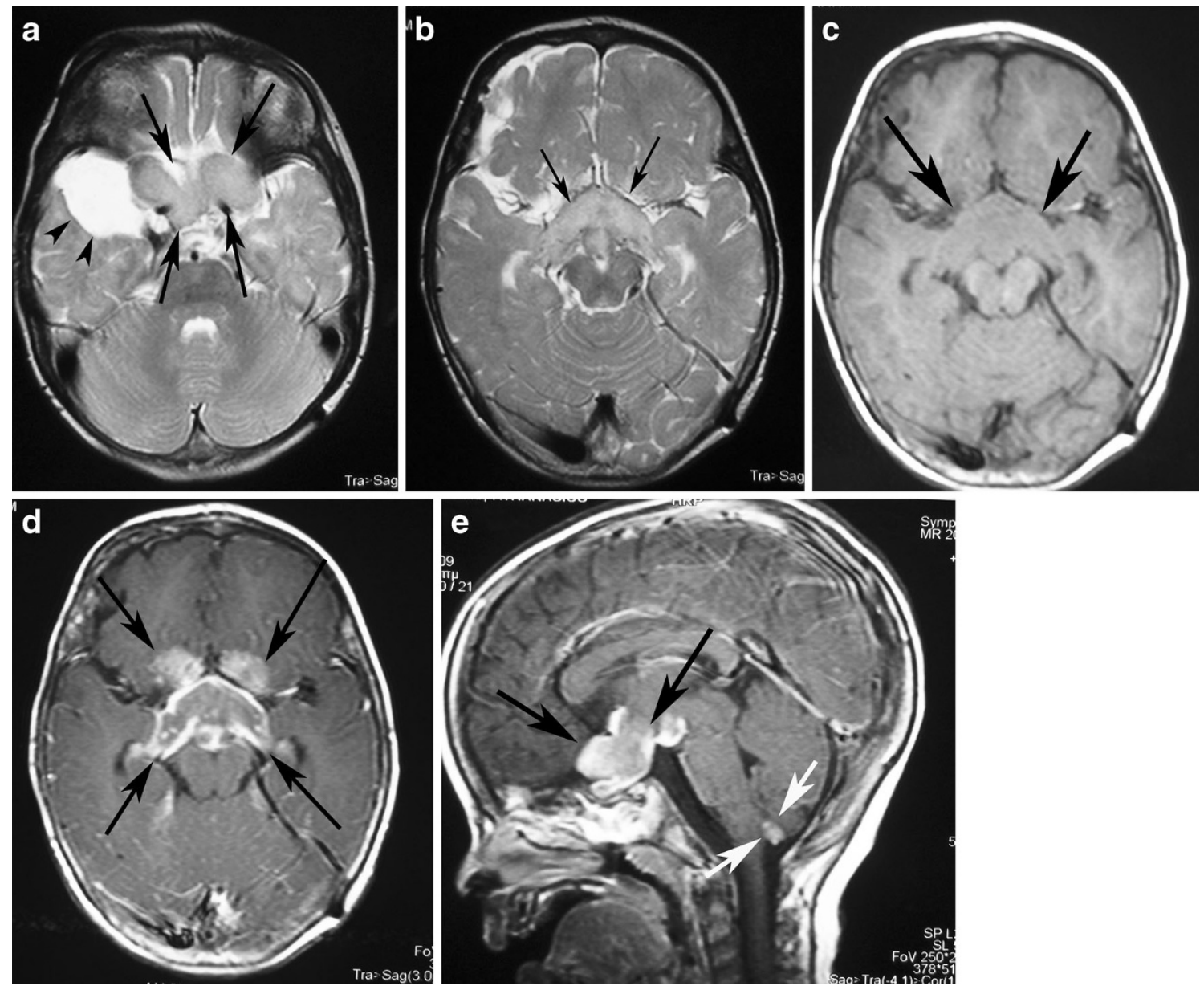

Fig. 12 A pilocytic astrocytoma involving optic pathways. a An axial T2-weighted image shows a large mass originating in the region of the optic chiasm/hypothalamus (arrows). Note the arachnoid cyst in the right middle cranial fossa (arrowheads). b An axial T2-weighted image in a higher level shows the hyperintense tumour extending to the optic radiations (arrows). On this T1-weighted image (c), the mass is isointense compared with grey matter. T1-weighted axial (d) and sagittal (e) postcontrast images show heterogeneous enhancement extending anteriorly towards the optic nerves and posteriorly towards the optic tracts. Note the enhancing nodule dorsal to the medulla due to dissemination of the pilocytic astrocytoma (arrows)

Investigators have demonstrated marked elevation of relative cerebral blood volume $(\mathrm{rCBV})$ in cases of haemangioblastoma and mild elevation in cases of PA, with statistically significant differences. Kumar et al. reported mean relative cerebral blood volumes of 7.7 in patients with haemangioblastomas and 1.8 in patients with PAs. Therefore, a finding of elevated rCBV levels should lead to a high preoperative suspicion of haemangioblastoma [26].

Gross total resection is the treatment of choice for CPA and is often curative. Progression of residual disease can be controlled by tumour re-excision and stereotactic radiosurgery $[27,28]$. In the event of biopsyproven pilocytic astrocytoma with anaplastic features, radiation therapy and/or chemotherapy will be required [12]. 

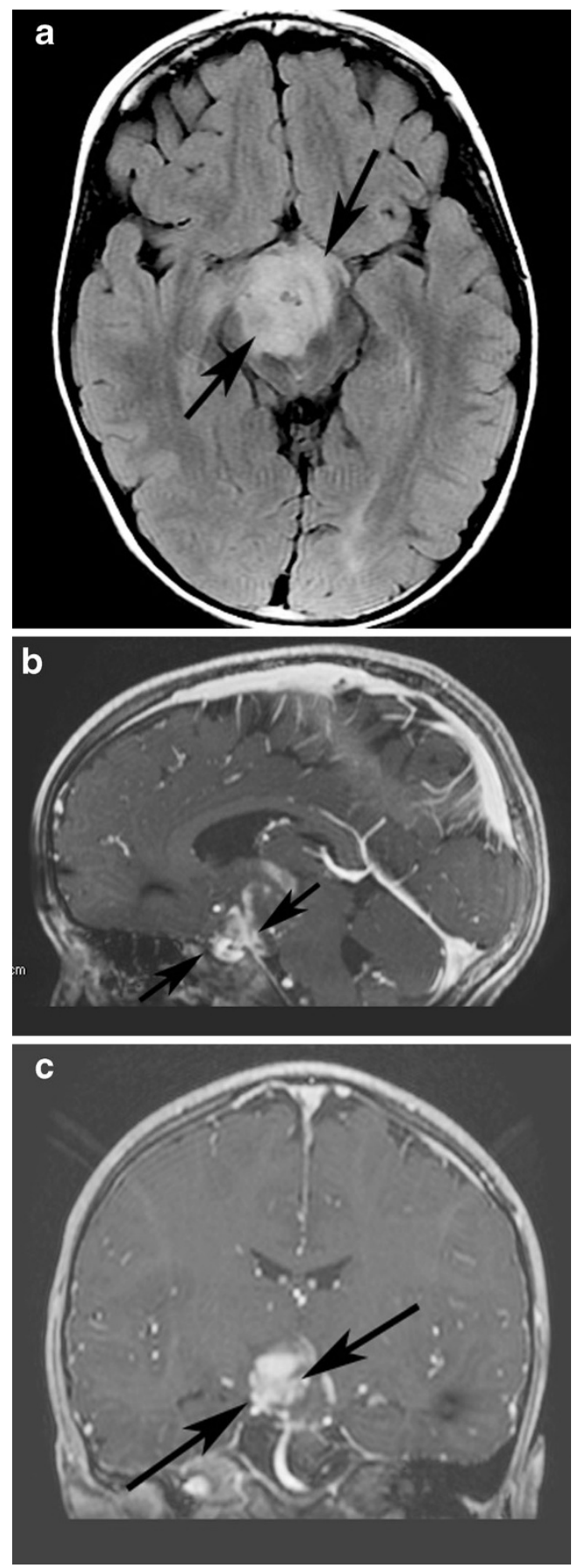

Fig. 13 Pilomyxoid astrocytoma in a 5-year-old girl. a An axial FLAIR image shows a large solid lobulated suprasellar mass with uniform hyperintensity (arrows). Postgadolinium sagittal (b) and coronal (c) T1weighted images reveal a homogeneously enhancing suprasellar infiltrative tumour (arrows)

\section{Brainstem PA}

Brainstem tumours (BSTs) account for 10-15\% of primary intracranial tumours in children. They occur at a mean age of
7 years and are usually divided between diffuse BSTs and non-diffuse or focal BSTs. BSTs are almost exclusively astrocytomas. Diffuse BSTs are usually fibrillary astrocytomas or malignant neoplasms, while focal BSTs are mainly PAs.

PA of the brainstem (BPA) in children can be located in the midbrain (in the pons), but is more frequently located in the medulla. Involvement of the upper cervical cord is sometimes noted [29-31]. Adult BPA is very rare. Guillamo et al. [32] report only a single case of PA in 32 biopsied adult brainstem gliomas.

BPA expands the brainstem and is typically associated with an exophytic growth, usually from its dorsal surface [20, 31]. It is characterised by sharp margins with cyst-like areas. The dorsal extension is a result of the inability of the low-grade tumour to infiltrate caudally below the decussations of the corticospinal tracts and medial lemnisci at the craniocervical junction. Therefore, dorsally exophytic tumours should be considered focal BSTs. However, ventral exophytic PAs have also been observed. Diffusely infiltrative brainstem gliomas are usually fibrillary astrocytomas located in the ventral pons, which present with abducens palsy, often engulf the basilar artery, and are associated with a grim prognosis [32]. Symptoms and signs are usually related to increased intracranial pressure. Nausea, vomiting, and ataxia with evidence of torticollis, papilledema, and nystagmus palsies of the sixth and seventh cranial nerves are usually observed at physical examination.

On CT BPA presents as a heterogeneous mass that expands the pons, distorts the fourth ventricle, and results in a degree of hydrocephalus. The mass is predominantly of low attenuation, with areas of intense enhancement on postcontrast images. BPAs are very bright on T2-weighted MRI. Thus, they can be differentiated from ependymomas, which are isodense to grey matter on CT and isointense on T2-weighted MRI. In addition, dorsally exophytic tumours have been observed to push the fourth ventricle upward, in contrast to ependymomas, which originate within the wall of the fourth ventricle and expand it. After the administration of contrast media, BPA exhibits inconsistently homogeneous or heterogeneous enhancement (Figs. 9, 10, and 11).

Proton MRS and perfusion imaging may be useful to differentiate low-grade PA from high-grade tumours in that lower grade glial tumours have lower choline peaks and smaller blood volume than higher grade glial tumours (Fig. 9f,g). However, pilocytic astrocytomas may have relatively high choline and lactate peaks and relatively high blood volumes, thus mimicking high-grade tumours (Fig. 10c,d). The distinction between the more biologically aggressive fibrillary astrocytoma and PA is more than an academic curiosity, since the fibrillary brainstem astrocytoma is associated with a dismal prognosis compared with the excellent outlook associated with the pilocytic variety [33]. 
Fig. 14 A pilocytic astrocytoma of the optic nerve in a 3-year-old girl with NF1. a An axial T2weighted image reveals characteristic kinking of the enlarged right optic nerve within the intraconal compartment and enlargement (arrow) of the posterior extraconal compartment. Note the characteristic NF1 bright lesions in the cerebellar hemispheres (arrowheads). b A coronal STIR image shows the enlarged right optic nerve (arrow) in comparison with the normal left optic nerve (arrowhead). On these contrastenhanced axial (c) and sagittal (d) T1-weighted images, intense enhancement of the extraconal component is observed (arrows)
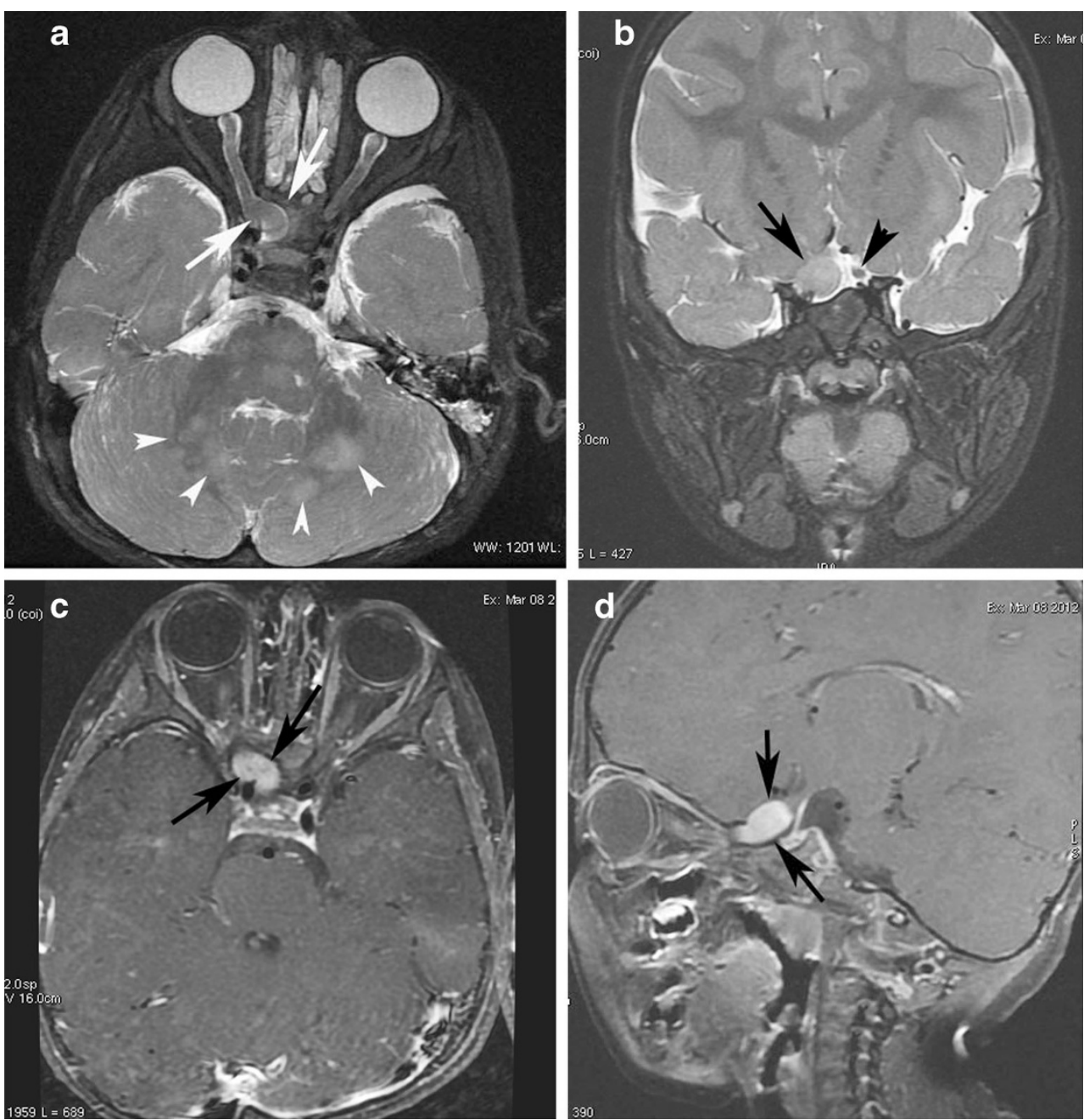

Management of BPA is a difficult challenge. Surgical treatment must cope with the difficulties of both deep location and eloquent area tumours. The tumour can be controlled by partial surgical removal, and a residual tumour can sometimes decrease in size after surgery. Gross total removal of these tumours, although difficult, may be performed [34].

BPA is associated with a relatively good prognosis in children and adults $[32,35]$. Ahmed et al. recently reported long-term overall survival of 14.8 years in a series of 48 children, with respective 1-, 5-, and 10-year overall survival rates of $85 \%, 67 \%$, and $59 \%$ [36].

\section{Supratentorial manifestations}

Chiasmatic/hypothalamic PA

Gliomas originating in the optic chiasm often enlarge and involve the hypothalamus; similarly, astrocytomas arising in the hypothalamus often grow anteriorly and inferiorly to involve the optic chiasm. Because the primary site of origin cannot be determined in many cases, tumours arising from these two locations are often discussed together. Astrocytomas of the optic chiasm and hypothalamus make up $10 \%$ to $15 \%$ of supratentorial tumours in children; males and females are approximately equally affected. One-third of patients have neurofibromatosis type 1 (NF1) [37].

The most common symptom of hypothalamic/optic pathway PA is diminished visual acuity. Endocrine dysfunction, most commonly short stature secondary to reduced growth hormone, is usually observed. Large tumours produce hydrocephalus secondary to extension into the anterior third ventricle and obstruction at the level of the foramen of Monro.

MRI provides precise demarcation of tumour extension and in many cases allows accurate preoperative diagnosis based on MRI findings [38]. Involvement of the optic pathway causes enlargement of the optic chiasm, nerve, and tracts. Chiasmatic/hypothalamic PAs are hypointense on T1- 
weighted sequence and hyperintense on T2-weighted and FLAIR sequences. When large and bulky, tumours are typically heterogeneous and mainly solid, with mild or marked enhancement after the intravenous administration of contrast media (Fig. 12). Using fat-suppression techniques to eliminate fat signal from the skull base can increase the value of contrast-enhanced MR images of this area.

Cystic areas and trapped pools of CSF are sometimes noted. The indolent growth rate of chiasmatic/hypothalamic PA and its tendency to infiltrate along the arachnoid with secondary fibrotic changes might explain the secondary development of arachnoid cysts (Fig. 12). This phenomenon has not been reported in association with other brain tumours [9].

Differential diagnosis in children should include craniopharyngioma, germinoma, and Langerhans cell histiocytosis. In adults, differential diagnosis should include pituitary macroadenoma, sellar meningioma, craniopharingioma, metastases (more often from breast and lung primary tumours), and lymphoma [39].

PMA is a rare variant of PA. It develops more frequently in the suprasellar area. PMAs are more aggressive masses and are mainly solid with uniform or heterogeneous rim enhancement. They exhibit higher rates of intratumoral haemorrhage and frequent local recurrence, and are often associated with leptomeningeal dissemination [40] (Fig. 13). Chiasmatic/ hypothalamic PMAs reportedly display higher choline/Cr ratios outside their enhancing tumour margins, which likely reflects their more aggressive behaviour [41].

The goal of surgery in cases of chiasmatic/hypothalamic PA is primarily to establish a histological diagnosis; if a typical low-grade astrocytoma is encountered, then limited resection is performed. Large masses that obstruct the foramen of Monro are debulked to relieve ventricular obstruction. The majority of such patients respond to platinum-based chemotherapy. Chemotherapy can also improve serious visual dysfunction, and a chemotherapy-first strategy can preserve the cognitive outcome of patients, who thereby avoid the need for radiotherapy [42]. Chemotherapy and radiation therapy can provide good control of the disease, with 5-year overall survival reported at $>90 \%$ [43]. Even when leptomeningeal gliomatosis presents, craniospinal irradiation and temozolomide can be very effective in disease control [44].

\section{Optic nerve PA}

Anterior optic pathway gliomas are usually PAs presenting during the first decade of life. More than one-half of patients have NF1 [45]. Segal et al. [46] reviewed 331 patients with NF1 and reported the development of optic nerve glioma in $13 \%$ of them. Bilateral tumours are almost pathognomonic for NF1.
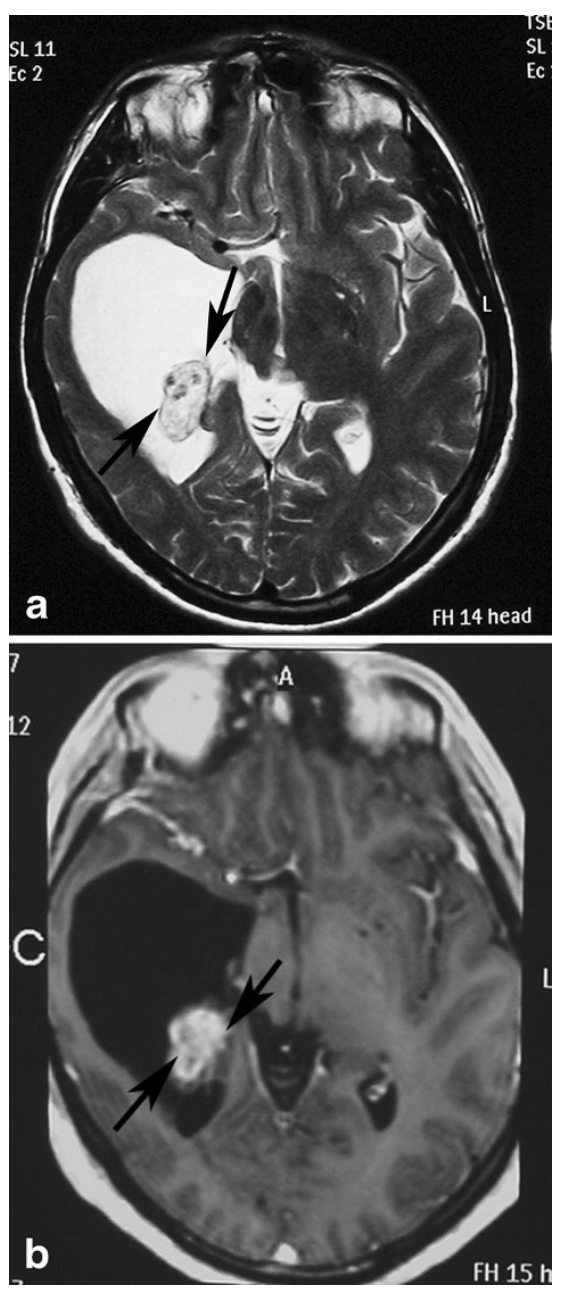

Fig. 15 Classical appearance of a hemispheric pilocytic astrocytoma in a 45-year-old man. a An axial T2-weighted image demonstrates a hyperintense cystic component and a less hyperintense solid nodule within the lateral ventricle (arrows). b A contrast-enhanced axial T1-weighted image reveals intense enhancement of the solid nodule (arrows) and lack of enhancement of the cystic portion

Anterior optic pathway PA exhibits different biological behaviour in patients with and without NF1. Isolated optic involvement, preservation of the optic nerve configuration, smaller tumour size, absence of symptoms, stability or slow growth, and even spontaneous regression are more often observed in patients with NF1. In comparison, chiasmal involvement, altered optic nerve configuration, greater tumour size, presence of symptoms, and local growth are more often encountered in patients without NF1 [45, 47].

MRI displays fusiform enlargement of the optic nerve, usually with kinking or tortuosity and contrast enhancement after the intravenous administration of gadolinium (Fig. 14). Infiltration of the perineural subarachnoid space, cystic components, and optic canal enlargement are sometimes observed. 

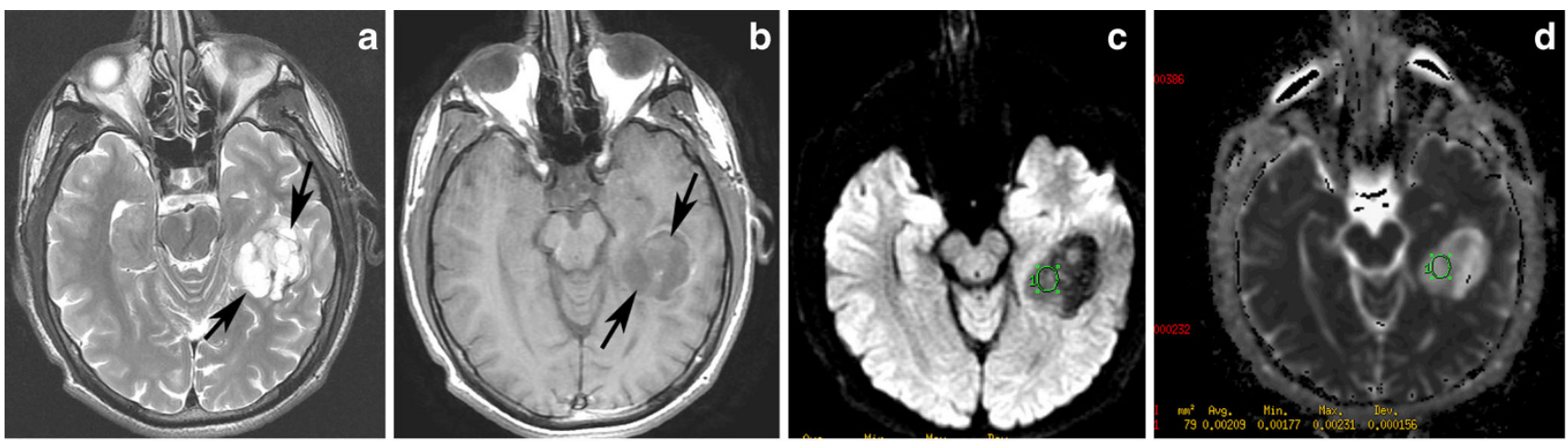
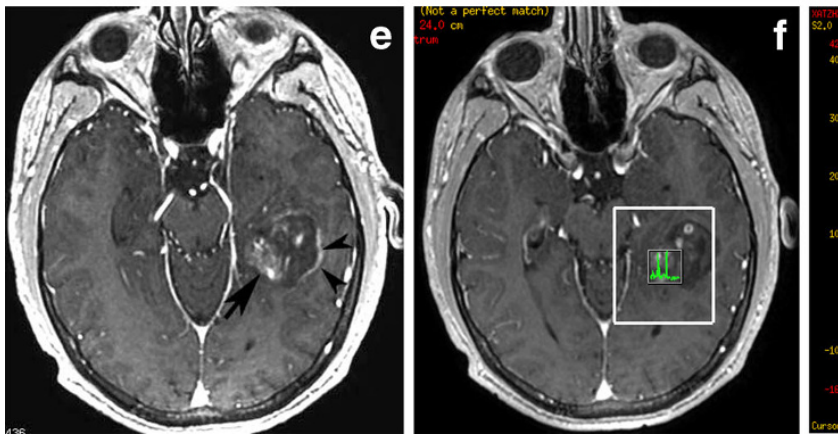

Fig. 16 Hemispheric pilocytic astrocytomas in a 26-year-old man. a An axial T2-weighted image shows a temporally located, lobular mass that is very hyperintense (arrows) without vasogenic oedema. b On this T1weighted image, the lesion is hypointense compared with grey matter (arrows). $\mathbf{c}$ The lesion exhibits low signal on diffusion-weighted imaging,

Treatment is required only in symptomatic, growing tumours. Resection is reserved for eyes with poor or absent vision, for cosmetic reasons, or because of exposure keratopathy. Radiotherapy and chemotherapy can be used to control tumour growth; however, radiotherapy should be avoided in patients younger than 5 years of age [48].

The prognosis for anterior optic pathway gliomas is very good; a 10-year progression-free survival rate of $72 \%$ has been reported (in contrast to $58 \%$ for posterior optic pathway gliomas) [49].

\section{Hemispheric PA}

Among the various age groups of patients with PA, the major tumour location differs in prevalence. In children, up to $67 \%$ of patients present with cerebellar lesions; in adults, approximately $55 \%$ of patients present with supratentorial lesions. Although juvenile PAs are less common in the cerebral hemisphere, they constitute $20 \%$ of supratentorial brain tumours.

Headache, seizure activity, hemiparesis, ataxia, nausea, and vomiting are common clinical manifestations of hemispheric pilocytic astrocytomas (HPAs). The occurrence of seizure activity generally indicates cortical grey matter involvement
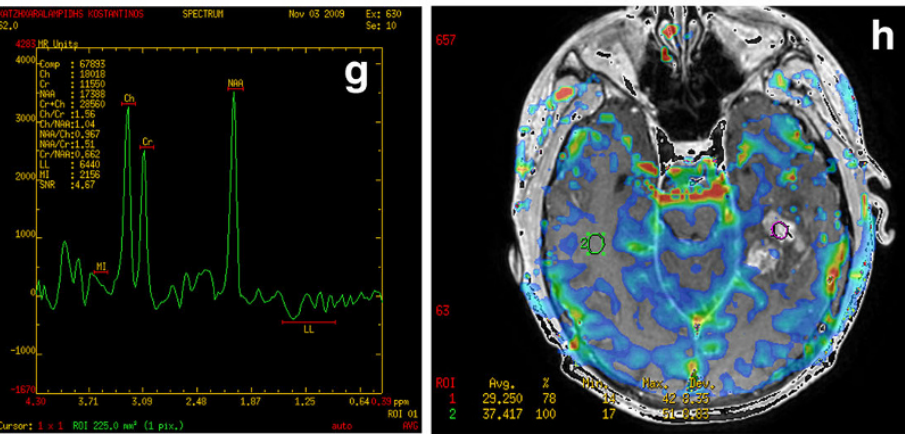

with high signal intensity on an ADC map (d). e On this post-contrast, T1-weighted image, nodular (arrow) and peripheral rim enhancements (arrowheads) are visible. f, g MRS with TE $144 \mathrm{~ms}$ revealed an elevated choline peak without reduction of the NAA peak. h Perfusion MRI reveals low rCBV in the solid (enhanced) part of the tumour

[9]. The tumours have no characteristic location, although in the paediatric population they tend to occur deep within the hemispheres and involve the basal ganglia or thalamus more frequently than do adult tumours.

The most characteristic imaging finding is a cystic mass with an enhancing mural nodule, usually contiguous with the ventricular system. In one-half of HPA cases, the nodule has a deep location (Fig. 15). However, HPAs usually appear as medially located masses that are very hyperintense on T2weighted and FLAIR images. They elicit little or no vasogenic oedema in the surrounding white matter and enhance after the injection of gadolinium [49]. The enhancement of the solid component of PA may be due to rich vascularity or to focal disturbance of the blood-brain barrier [50] (Figs. 16 and 17). Spontaneous intratumoral haemorrhage has also been described [51]. Mixed pilocytic and fibrillary astrocytomas are encountered; malignant transformation of a PA rarely occurs [6]. On diffusion-weighted imaging, solid areas of HPA have higher ADC values than high-grade hemispheric tumours [52] (Figs. 16c and 17c).

Previous reports of MRS performed on solid portions of PA tumours have documented elevations in the choline-to-NAA ratio [53] to a lesser extent than in higher grade neoplasms (Fig. 16f,g). The well-known positive correlation between 

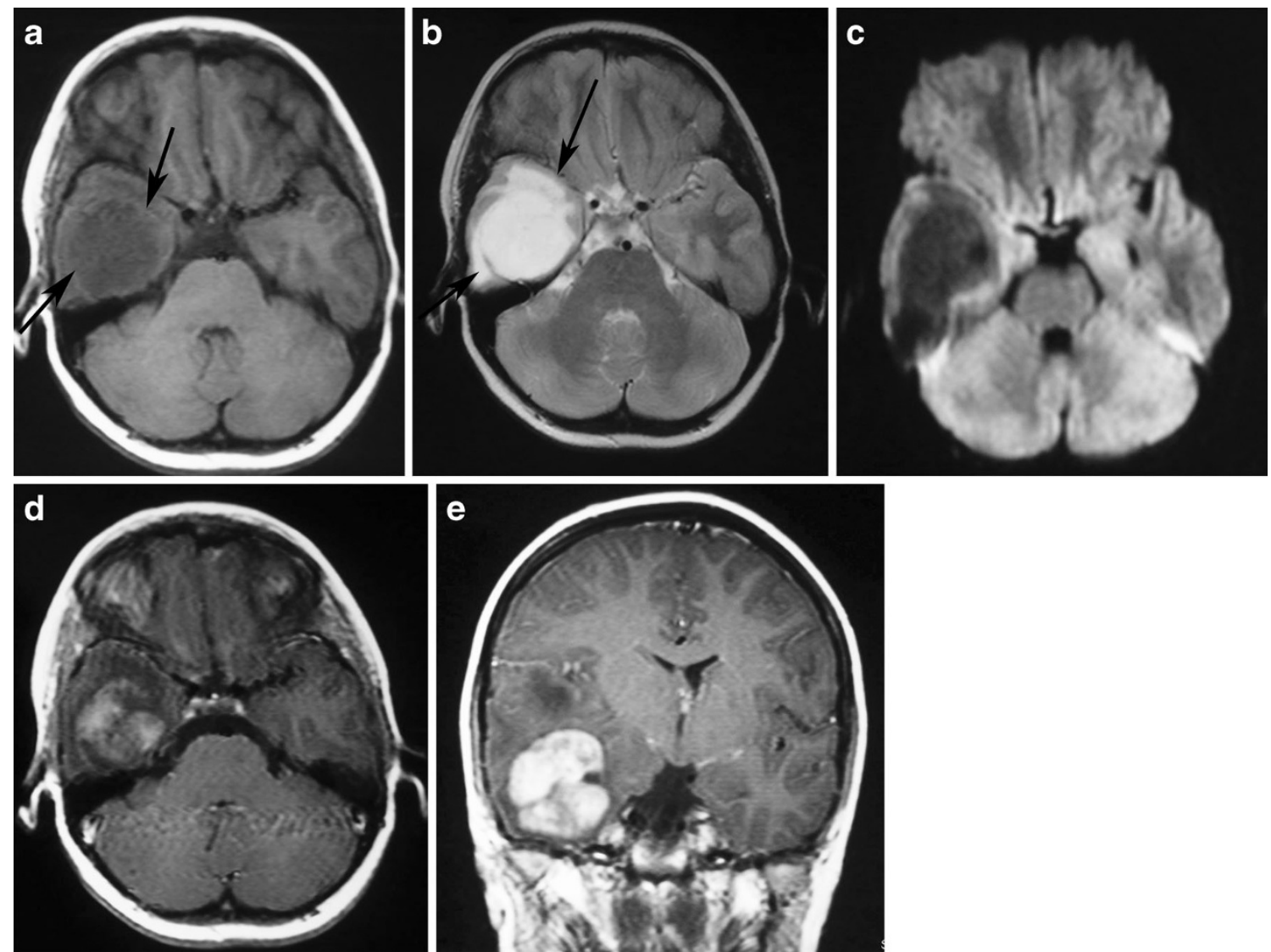

Fig. 17 Supratentorial pilocytic astrocytoma with solid enhancement and vasogenic oedema. a An axial T1-weighted image shows a wellcircumscribed, hypointense cerebral mass (arrows). b An axial T2weighted image shows a hyperintense mass. Note the vasogenic oedema

increased choline levels and the glioma grade appears to be violated by WHO grade I PAs, which exhibit a wide range of choline values, with a marked increase in some cases. No significant differences have been identified in MRS metabolite profiles between paediatric and adult PAs [54].

PAs have a low maximum $\mathrm{rCBV}$ ratio $(<1.5)$ and exhibit a characteristic type of signal intensity time curve with an increase in signal intensity above baseline caused by the massive leakage of contrast medium into the interstitial space [51] (Fig. 16h). Differential diagnosis should include other glial tumours, as well as metastases in adults and primitive neuroectodermal tumours in children. While high-grade gliomas are usually characterised by irregular margins and perifocal oedema, haemorrhagic features have also been encountered. Fibrillary astrocytomas, oligodendrogliomas, and gangliogliomas usually do not display the marked enhancement observed in PA. Calcifications have been detected in oligodendrogliomas and gangliogliomas, as well as scalloping/erosion of the inner table of the calvaria in cases of peripherally located tumours. around the mass (arrows). $\mathbf{c}$ The lesion exhibits low signal on diffusionweighted imaging. Contrast-enhanced axial (d) and (e) T1-weighted images demonstrate inhomogeneous enhancement of the mass

The first-line therapy for HPA is complete surgical resection. Adjuvant chemotherapy and radiotherapy are reserved for recurrent or progressive inoperable disease.

\section{Conclusion}

In summary, this pictorial review presents imaging appearances and the differential diagnosis of PA according to tumour location. MRI with conventional sequences and advanced techniques provides useful information regarding characteristics of this low-grade tumour. High ADC values can be used in the clinical setting as a reliable factor indicating low cellularity of PA. Metabolite ratios of MRS and rCBV measurements on perfusion exhibit inferior diagnostic performance, since pilocytic astrocytomas may have relatively high choline and lactate peaks and relatively high blood volumes, thus mimicking high-grade tumours. Recognition of radiologic features and familiarity with the clinical course and sites of potential 
involvement are essential for making the correct diagnosis and helpful for management decisions.

Open Access This article is distributed under the terms of the Creative Commons Attribution License which permits any use, distribution, and reproduction in any medium, provided the original author(s) and the source are credited.

\section{References}

1. Tibbetts KM, Emnett RJ, Gao F, Perry A, Gutmann DH, Leonard JR (2009) Histopathologic predictors of pilocytic astrocytoma event-free survival. Acta Neuropathol 117(6):657-665

2. Scheithauer BW, Hawkins C, Tihan T, Vandenberg SR, Burger PC (2007) Pilocytic astrocytoma. In: Louis DN, Ohgaki H, Wiestler OD, Cavenee WK (eds) WHO classification of tumours of the central nervous system, 4th edn. IARC, Lyon, pp 14-21

3. Manik M, Rajesh S, Poonam S, Anchal G (2012) Densely calcified pilocytic astrocytoma in the sellar/suprasellar region. Int $\mathrm{J}$ Clin Pediatr 1:129-132

4. Burkhard C, Di Patre PL, Schüler D, Schüler G, Yas, Argil MG, Yonekawa $\mathrm{Y}$ et al (2003) A population-based study of the incidence and survival rates in patients with pilocytic astrocytoma. J Neurosurg 98(6):1170-1174

5. Forsyth PA, Shaw EG, Scheithauer BW, O'Fallon JR, Layton DD Jr, Katzmann JA (1993) Supratentorial pilocytic astrocytomas: a clinicopathologic, prognostic, flow cytometric study of 51 patients. Cancer 72:1335-1342

6. Katsetos CD, Krishna L (1994) Lobar pilocytic astrocytomas of the cerebral hemispheres. I. Diagnosis and nosology. Clin Neuropathol 13:295-305

7. Brat DJ, Burger PC (1998) Cerebral pilocytic astrocytoma: distinction from infiltrating fibrillary astrocytomas. Pathol Case Rev 3:290 295

8. Cyrine S, Sonia Z, Mounir T, Badderedine S, Kalthoum T, Hedi K, Moncef M (2012) Pilocytic astrocytoma: a retrospective study of 32 cases. Clin Neurol Neurosurg 115(8):1220-1225

9. Koeller KK, Rushing EJ (2004) Pilocytic astrocytoma: radiologicpathologic correlation. Radiographics 24:1693-1708

10. Christoforidis G, Drevelegas A, Bourekas E, Karkavelas G (2011) Low grade gliomas pp 84 in Imaging of Brain Tumors with Histological Correlation Ed. A. Drevelegas second edition Springer

11. Cha S (2006) Update on brain tumor imaging: from anatomy to physiology. AJNR 27:475-487

12. Shibao S, Kimura T, Sasaki H et al (2012) Hemmorhagic onset of cerebellar pilocytic astrocytoma in an adult: a case report and review of the literature implying a possible relation of degenerative vascular changes to the massive intratumoral hemorrhage. Brain Tumor Pathol 29(2):96-102

13. Bian SX, McAleer MF, Vats TS, Mahajan A, Grosshans DR (2012) Pilocytic astrocytoma with leptomeningeal dissemination. Childs Nerv Syst 29(3):441-450

14. Kayama T, Tominaga T, Yoshimoto T (1996) Management of pilocytic astrocytoma. Neurosurg Rev 19(4):217-220

15. Davis FG, McCarthy BJ (2000) Epidemiology of brain tumors. Curr Opin Neurol 13:635-640

16. Poretti A, Meoded A, Huisman TA (2012) Neuroimaging of pediatric posterior fossa tumors including review of the literature. J Magn Reson Imaging 35(1):32-47
17. Hayostek CJ, Shaw EG, Scheithauer B, O'Fallon JR, Weiland TL, Schomberg PJ, Kelly PJ, Hu TC (1993) Astrocytomas of the cerebellum. A comparative clinicopathologic study of pilocytic and diffuse astrocytomas. Cancer 72(3):856-869

18. Pencalet P, Maixner W, Sainte-Rose C et al (1999) Benign cerebellar astrocytomas in children. J Neurosurg 90(2):265-273

19. Lee YY, Van Tassel P, Bruner JM, Moser RP, Share JC (1989) Juvenile pilocytic astrocytomas: CT and MR characteristics. AJR Am J Roentgenol 152:1263-1270

20. Arai K, Sato N, Aoki J et al (2006) MR signal of the solid portion of pilocytic astrocytoma on T2-weighted images: is it useful for differentiation from medulloblastoma? Neuroradiology 48(4):233-237

21. Rumboldt Z, Camacho DLA, Lake D et al (2006) Apparent diffusion coefficients for differentiation of cerebellar tumors in children. AJNR 27:1362-1369

22. Pavlisa G, Pavlisa G, Rados M (2011) Diffusion differences between pilocytic astrocytomas and grade II ependymomas. Radiol Oncol 45(2):97-101

23. Hwang JH, Egnaczyk GF, Ballard E et al (1998) Proton MR Spectroscopic characteristics of pediatric pilocytic astrocytomas. AJNR 19:535-540

24. Panigraphy A, Krieger MD, Gonzalez-Gomez I et al (2006) Quantitative short echo time 1H-MR Spectroscopy of untreated pediatric brain tumors: preoperative diagnosis and characterization. AJNR 27:560-572

25. Sutton LN, Wang Z, Gusnard D et al (1992) Proton magnetic resonance spectroscopy of pediatric brain tumors. Neurosurgery 31:195-202

26. Kumar VA, Knopp EA, Zagzag D (2010) Magnetic resonance dynamic susceptibility-weighted contrast-enhanced perfusion imaging in the diagnosis of posterior fossa hemangioblastomas and pilocytic astrocytomas: initial results. J Comput Assist Tomogr 34(6):825-829

27. Kano H, Kondziolka D, Niranjan A et al (2009) Stereotactic radiosurgery for pilocytic astrocytoma part 1: outcomes in adult patients. $\mathrm{J}$ Neurooncol 95(2):211-218

28. Kano H, Niranjan A, Kondzioka D et al (2009) Stereotactic radiosurgery for pilocytic astrocytoma part 2: outcomes in pediatric patients. J Neurooncol 95(2):219-229

29. Young Poussaint Y, Yousuf N, Barnes PD et al (1999) Cervicomedullary astrocytomas of childhood: clinical and imaging follow-up. Pediatr Radiol 29(9):662-668

30. Fisher PG, Breiter SN, Carson BS et al (2000) A clinicopathologic reappraisal of brain stem tumor classification. Identification of pilocytic astrocytoma and fibrillary astrocytoma as distinct entities. Cancer 89(7):1569-1576

31. Kestle J, Townsend JJ, Brockmeyer DL, Walker ML (2004) Juvenile pilocytic astrocytoma of the brainstem in children. J Neurosurg 101: $1-6$

32. Guillamo JS, Monjour A, Taillandier L et al (2001) Braistem gliomas in adults: prognostic factors and classification. Brain 124:2528-2539

33. Burger PC, Breiter SN, Fisher PG (1996) Pilocytic and fibrillary astrocytomas of the brain stem: a comparative clinical, radiological, and pathological study. J Neuropathol Exp Neurol 55:640

34. Klein O, Grignon Y, Civit T, Pinelli C, Auque J, Marchal JC (2006) Childhood diencephalic pilocytic astrocytoma. A review of seven observations. Neurochirurgie 52(1):3-14

35. Kesari S, Kim RS, Markos V et al (2008) Prognostic factors in adult brainstem gliomas: a multicenter, retrospective analysis of 101 cases. J Neurooncol 88(2):175-183

36. Ahmed KA, Laack NN, Eckel LJ, Orme NM, Wetjen NM (2013) Histologically proven, low-grade brainstem gliomas in children: $30-$ year experience with long-term follow-up at Mayo Clinic. Am J Clin Oncol Jan 24 
37. Valdueza JM, Lohmann F, Dammann O et al (1994) Analysis of 20 primary surgically treated chiasmatic/hypothalamic pilocytic astrocytomas. Acta Neurochir 16:44-50

38. Sawamura Y, Kamada K, Kamoshima Y et al (2008) Role of surgery for optic pathway/hypothalamic astrocytomas in children. Neuro Oncol 10(5):725-733

39. Glastonbury CM, Osborn AG, Salzman KL (2011) Masses and malformations of the third ventricle: normal anatomic relationships and differential diagnosis. Radiographics 31: 1889-1905

40. Linscott LL, Osborn AG, Blaser S et al (2008) Pilomyxoid astrocytoma: expanding the imaging spectrum. AJNR 29: $1861-1866$

41. Morales H, Kwock L, Castillo M (2007) Magnetic resonance imaging and spectroscopy of pilomyxoid astrocytomas: case reports and comparison with pilocytic astrocytomas. J Comput Assist Tomogr 31(5):682-687

42. Sawamura Y, Kamada K, Kamoshima Y, Yamaguchi S, Tajima T, Tsubaki J, Fujimaki T (2008) Role of surgery for optic pathway/hypothalamic astrocytomas in children. Neuro Oncol 10(5):725-733

43. Gnekow AK, Kortmann RD, Pietsch T, Emser A (2004) Low-grade chiasmatic-hypothalamic glioma-carboplatin and vincristine chemotherapy effectively defers radiotherapy within a comprehensive treatment strategy - report from the multicenter treatment study for children and adolescents with a low-grade glioma-HIT-LGG 1996-of the society of Pediatric Oncology and Hematology (GPOH). Klin Padiatr 216(6):331-342

44. Aryan HE, Meltzer HS, Lu DC et al (2005) Management of pilocytic astrocytoma with diffuse leptomeningeal spread: two cases and review of the literature. Childs Nerv Syst 21(6): $477-481$
45. Chung EM, Specht CS, Schroeder JW (2007) Pediatric orbit tumors and tumorlike lesions: neuroepithelial lesions of the ocular globe and optic nerve. Radiographics 27:1159-1186

46. Segal L, Darvish-Zargar M, Dilenge ME et al (2010) Optic pathway gliomas in patients with neurofibromatosis type 1: follow-up of 44 patients. J AAPOS 14(2):155-158

47. Kornreich L, Blaser S, Schwarz M et al (2001) Optic pathway glioma: correlation of imaging findings with the presence of neurofibromatosis. AJNR 22:1963-1969

48. Lee AG (2007) Neuroophthalmological management of optic pathway gliomas. Neurosurg Focus 23(5):E1

49. Khafaga Y, Hassounah M, Kandil A et al (2003) Optic gliomas: a retrospective analysis of 50 cases. Int J Radiat Oncol Biol Phys 56(3): $807-812$

50. Grand SD, Kremer S, Tropres IM et al (2007) Perfusion-sensitive MRI of pilocytic astrocytomas: initial results. Neuroradiology 49(7): $545-550$

51. Li HM, Hsu SS, Wang JS et al (2008) Cerebral pilocytic astrocytoma with spontaneous intracranial hemorrhage in adults. J Chin Med Assoc 71(11):587-593

52. Porto L, Jurcoane A, Schwabe D, Kieslich M, Hattingen E (2012) Differentiation between high and low grade tumours in paediatric patients by using apparent diffusion coefficients. Eur J Paediatr Neurol 17(3):302-307

53. Hwang JH, Egnaczyk GF, Ballard E, Dunn RS, Holland SK, Ball WS Jr (1998) Proton MR spectroscopic characteristics of pediatric pilocytic astrocytomas. AJNR 19:535-540

54. Porto L, Kieslich M, Franz K, Lehrbecher T, Vlaho S, Pilatus U, Hattingen E (2010) Spectroscopy of untreated pilocytic astrocytomas: do children and adults share some metabolic features in addition to their morphologic similarities? Childs Nerv Syst 26(6):801-806 